\title{
Equity in health
}

\section{B Starfield}

\section{Meeting of the International Society for Equity in Health, Havana, Cuba, June 2000}

$\mathrm{T}$ his issue of the Journal of Epidemiol ogy and Community Health contains seven contributions that were originally presented as submitted papers to the first meeting of the International Society for Equity in Health, held in Havana, Cuba, in June 2000

These contributions, consisting of seven original scientific papers and the keynote address (by Sudhir Anand) are complemented by an additional set of "keynote vignettes" (also presented at the same meeting) to be published in subsequent issues of the journal. (They are short essays on priorities for research on equity in health, prepared by noted researchers in the field.)

The studies reported cover a wide variety of specific topics within the broader topic of equity in health. Two of the eight deal specifically with the meaning of equity in the context of health $^{12}$; two address inequities in health related to inequities in health services $^{3}{ }^{4}$; one addresses trends in disparities in infant mortality in the Americas $^{5}$; two concern inequity consequent to economic transitions ${ }^{67}$; and one discusses the relevance of the genetic revolution to the issue of social class disparities in health. ${ }^{8}$
All of the papers confront issues, which in one way or another are linked to two subjects of interest to the International Society for Equity in Health, which is devoted to encouraging research in the service of improving policy and practices directed at reducing inequities in health. Towards this end, the society has developed a working definition of equity in health: the absence of systematic and potentially remediable differences in one or more aspects of health across populations or population groups defined socially, economically, demographically, or geographically. This definition expands upon prior definitions ${ }^{9}{ }^{10}$ that have focused on fairness of opportunity to achieve health, for the purpose of making explicit the notion that inequities can be measured and tracked over time.

The papers also remind us that considerations of equity require not only attention to manifestations of ill health but also to risks to ill health as well as potential for improved health. This poses a daunting challenge to a research agenda. If equity in health requires equality of opportunities for health, and if these opportunities might be amenable to alterations in policy or practice, it

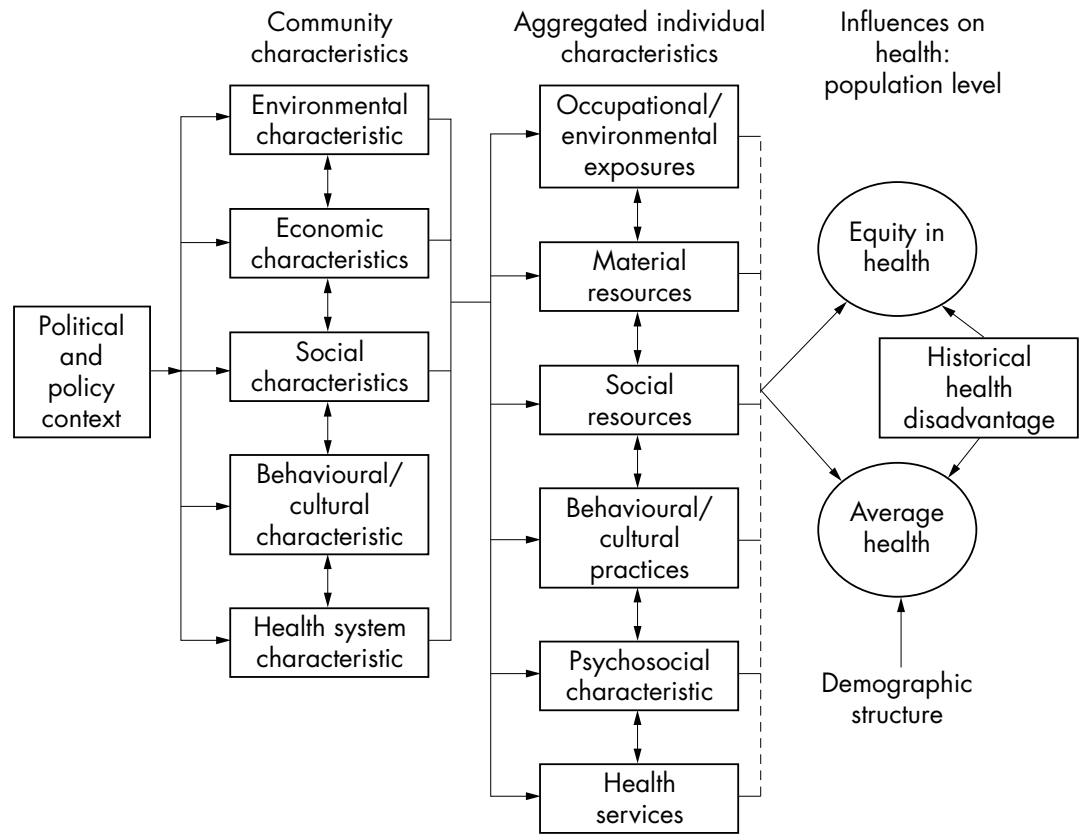

Figure 1 Influences on health at the population level. is clearly an imperative that the range of "opportunities" for influence be specified. Influences on health, and therefore on equity in health, are myriad; taking them all into account in trying to sort out those that are amenable to change from those that are not requires that we have both a clear conceptualisation of what they are as well as an idea, or theory, of how they inter-relate and inter-act to provide a cogent pathway for their impact. Although a few such models have been proposed and some ${ }^{11}$ widely cited, new knowledge that has subsequently accumulated makes it clear that the range and interaction of determinants is even more extensive than heretofore contemplated.

Figure 1 presents a more recent conceptualisation that attempts to take advantage of new research concerning factors that are associated with increased inequity in health. In contrast with previous schemata, it explicitly recognises that "average" health is not the only concern; distributions of health within and across populations are also relevant. Consistent with recent studies, ${ }^{12}$ it incorporates the wider ecological context of political and policy characteristics. It places the recently popular "income inequality" research within the more encompassing "economic characteristics", directly influenced by social and economic policy within defined political jurisdictions. Moreover, it explicitly recognises the need for analyses that are multilevel, in order to take into account characteristics that are aggregated to a population level from individual data; characteristics that reflect the context in which people live and work, and the more distal but still influential characteristics of health policy and politics. The diagram is a "work in progress", to be refined as more knowledge accumulates.

It is our hope that the formation of the International Society for Equity in Health can move the research and policy agenda further and faster than has been the case in the most recent two decades in which equity has received increasing attention. Comments on the definition and conceptualisation of determinants of health would be most welcome, as would participation in the society by interested parties. Information can be obtained on the web site (www.iseqh.org).

$J$ Epidemiol Community Health 2002; 56:483-484

Author's affiliations

B Starfield, School of Public Health, Johns Hopkins University, 624 N Broadway, Room 452, Baltimore, MD 21205, USA

Correspondence to: Dr B Starfield; bstarfie@jhsph.edu 


\section{REFERENCES}

1 Anand S. The concern for equity in health. $J$ Epidemiol Community Health

2002;56:485-7.

2 Chang W-C. The meaning and goals of equity in health. J Epidemiol Community Health 2002;56:488-91.

3 Gruen RL, Weeramanthri T, Bailie RS Outreach and improved access to specialist services for indigenous people in remote Australia: the requirements for sustainability $J$ Epidemiol Community Health 2002;56:517-21.

4 Aguilar MD, Lázaro P, Fitch K, et al. Gender differences in clinical status at time of coronary revascularisation in Spain. $J$ Epidemiol Community Health 2002;56:556-60.

5 Schneider MC, Castillo-Salgado C, Loyola-Elizondo $\mathrm{E}$, et al. Trends in infant mortality inequalities in the Americas:

1955-1995. J Epidemiol Community Health 2002;56:538-41.

6 Segall M, Tipping G, Lucas $H$. Economic transition should come with a health warning: the case of Vietnam. J Epidemiol Community Health 2002;56:497-505.

7 Ostry AS, Barroetavena M, Herschler R, et al. The effect of de-industrialisation on working conditions and self reported health in a sample of manufacturing workers. J Epidemiol Community Health 2002;56:506-9.

8 Holtzman NA. Genetics and social class. $J$ Epidemiol Community Health 2002;56:529-35.

9 Whitehead $M$. Who cares about equity in the NHS? BN 1994;308:1285-7.

10 Daniels N, Light D, Caplan R. Benchmarks of fairness for health care reform. New York: Oxford University Press, 1996.

11 Evans RG, Barer ML, Marmor TR. Why are some People healthy and others not? The determinants of health of populations. New York: Aldine Gruyter, 1994.

12 Navarro V, Shi L. The political context of social inequalities and health. Soc Sci Med 2001;52:481-91.

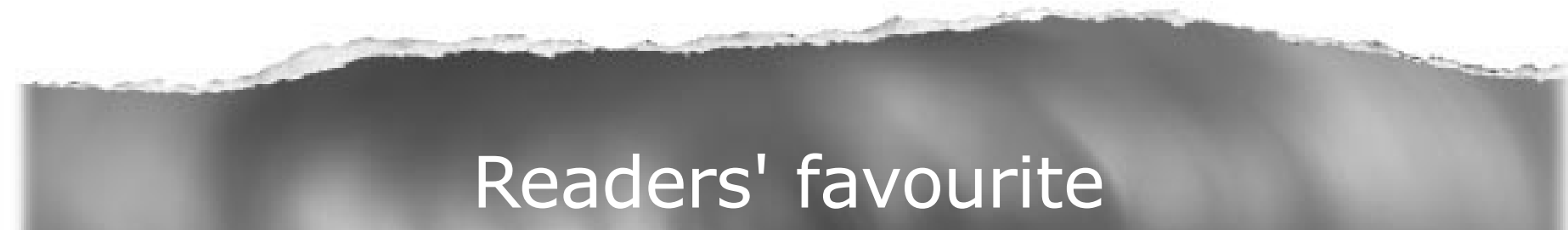

\section{Top 10}

Click on the "Top 10" button on the homepage to see which are the best read articles each month

www.jech.com 